KEYWORDS

Economic development

Production specialization

Production diversification

Industrial enterprises

Municipal government

Urban areas

Brazil

Eva Yamila da Silva Catela

Professor at the Federal University

of Santa Catarina

- evadasilvacatela@gmail.com

Flávio Gonçalves

Assistant Professor at the Federal University of Paraná

$\propto$ f.goncalves@ufpr.br

Gabriel Porcile

Assistant Professor at the Federal

University of Paraná

- porcile@ufpr.br
CEPAL REVIEW 101 - AUGUST 2010

\section{Brazilian municipalities:} agglomeration economies and development levels in 1997 and 2007

\author{
Eva Yamila da Silva Catela, Flávio Gonçalves \\ and Gabriel Porcile
}

$\mathrm{T}$

his article sets out to analyse the relation between agglomeration economies - both the Marshall-Arrow-Romer type (economies of specialization) and the Jacobs-Porter type (economies of diversification)and the unequal development of Brazilian municipalities as estimated by labour productivity (measured by the average wage). To that end, measures of specialization were constructed for 1997 and 2007, and the data were used to test the relation between the industrial specialization and diversification indices and productivity, using finite-mixture regressions to capture the heterogeneity of the data. The results confirm the duality existing between the north-northeast and south-southeast-centre-west regions of Brazil, which has been widely documented in other research. Nonetheless, this duality needs to be analysed further, because some cities do not reflect the general dynamic of their region. 


\section{I}

\section{Introduction}

Up to $80 \%$ of Brazil's population live in city areas which account for $90 \%$ of the country's gross domestic product (GDP) (Da Mata and others, 2007). This concentration of production is very heterogeneous, however, both from the spatial standpoint (in the country, between regions and within states) and with respect to the growth dynamic.

According to the theory of urban systems (Henderson, 1974; Dixit and Stiglitz, 1977; RiveraBatiz, 1988; Abdel-Rahman and Fujita, 1990; Krugman (1991; Anas and Xiong, 2003), a city can be viewed as the static or dynamic result of a balance between two forces: an agglomeration force, which benefits individuals and firms located close to one another; and a dispersion force, which generates costs from this proximity. The first of these tendencies provides a rationale for the existence of cities, whereas the second limits their size. The optimal city size is the result of the tension that exists between location economies, which act as an amalgamating force, and urban density, which tends to disperse the population.

The literature distinguishes two types of agglomeration that produce positive externalities for the existence of cities: external economies of location, or Marshall-Arrow-Romer externalities (Abdel-Rahman and Anas, 2004), which arise from knowledge transfers within an industry or between complementary ones; and urbanization or JacobsPorter externalities, generated by the transfer of knowledge between industries. These models stress the importance of diversity for improving productivity and economic efficiency, and suggest that a country's growth is enhanced by the heterogeneity of its cities. Empirical tests show that efficiency gains are significant (Quigley, 1998).

This article aims to describe some of the characteristics of the process of specialization and diversification in manufacturing industry in Brazil's urban municipalities. To that end, measures of

$\square$ The authors gratefully acknowledge support received from the Senior Staff Training Coordination Unit [Coordenação de Aperfeiçoamento de Pessoal de Nível Superior - CAPES]. specialization and diversification were constructed, and the selected municipalities were classified in homogeneous groups in terms of their industrialization type. The data were used to empirically test the relation between city productivity (measured by the average wage of its workers) and industrial specialization and diversification economies in the years 1997 and 2007. This analysis makes it possible to identify municipalities which display a similar development pattern, despite belonging to different states, regions or micro-regions. ${ }^{1,2}$ The identification process uses the clusters model, which makes it possible to group homogeneous observations within a heterogeneous dataset. In addition to performing this grouping, finite mixture regressions were estimated. The methodology makes it possible to estimate regressions for differentiated groups, taking explicit account of heterogeneity explicit through discontinuities in the observed relations.

This article is divided into seven sections, including the introduction. Section II considers the theoretical underpinnings of agglomeration economies and their influence on worker productivity, and also refers to a number of empirical tests. Section III presents and describes the data, while section IV establishes the diversification and specialization measures used and briefly characterizes Brazil's urban municipalities in terms of these measures. Section V presents a $\mathrm{k}$-means clustering analysis, and section VI sets out the econometric results of the finite-mixture regression model. Section VII provides conclusions and final comments.

\footnotetext{
1 Brazil is geographically divided into five regions, as defined in 1969 by the Brazilian Institute of Geography and Statistics (IBGE), namely: (i) the centre-west (consisting of the states of Goiás, Mato Grosso, Mato Grosso do Sul and the federal district); (ii) the northeast (Maranhão, Piauí, Ceará, Rio Grande do Norte, Paraíba, Pernambuco, Alagoas, Sergipe, Bahia); (iii) the north (Acre, Amazonas, Roraima, Rondônia, Pará, Amapá, Tocantins); (iv) the southeast (Minas Gerais, Espírito Santo, Rio de Janeiro, São Paulo) and; (v) the south (Paraná, Santa Catarina, Rio Grande do Sul).

2 Micro-regions are areas that group together municipalities with relatively homogeneous physical, social and economic characteristics, within a given state.
} 


\section{II}

\section{Agglomeration externalities, city heterogeneity and economic growth}

How do agglomeration economies and a city's size influence productivity, the level of output, and the well-being of its citizens? This section firstly describes the various dimensions of agglomeration economies, to show how they affect the productivity and economic growth of a city.

Rosenthal and Strange (2004) identify three dimensions of agglomeration: geographic, temporal and industrial. The geographic dimension refers to the existence of agglomeration externalities associated with distance. The literature establishes that the geographic scope of location economies is limited -as distance increases, agglomeration economies fade, as confirmed by Henderson (2003 and Rosenthal and Strange (2003). These authors make an analysis of the geographic scope of agglomeration economies, in which a firm's environment is defined by constructing concentric rings according to the postal code of the city in which the firm is located. Some authors specializing in geographical economics argue that space-limited positive externalities may affect the growth of the economy at large. Thus, the spatial distribution of the economy would have a considerable effect on economic activity and the growth of the economy as a whole (Baldwin and Martin, 2004).

The temporal dimension provides a framework for analyzing how an industry's past affects its current growth. The key issue is whether agglomeration economies are dynamic or static. The dynamic effect relates to knowledge spillovers, since knowledge accumulation takes time, and workers' skills increase as time passes. Thus, the temporal scope of the agglomeration can be seen as a historical component. Cities with higher levels of specialization are likely to grow more slowly, which would show that economies of urbanization promote their growth. Henderson, Kuncoro and Turner (1995) argue that a city's characteristics may affect its growth over a period of 20 years or longer. This effect may be direct, or else it may be indirect, through an accumulation of short-run direct effects.

The industrial dimension shows that productive clusters generate increasing returns in a city's industry. What are the nature and sources of the increasing returns produced by these clusters? Marshall (1920) suggests three sources: (i) increases of scale within the firm as production expands; (ii) a parallel labour-market cluster which improves the search for workers with the skills that firms need (integrated labour markets); and (iii) the existence of knowledge spillovers within industries, which generate knowledge externalities for both workers and firms. Other sources recently suggested include local-market effects.

In the first of these sources, economies of scale, or indivisibilities within the firm, encapsulate the basic rationale for the existence of cities: if there were no economies of scale in production, it would be better for economic activities to be dispersed to avoid transport costs. The second factor relates to the sharing of productive inputs. Krugman (1993) explains how the easy availability of specialized workers in metropolitan areas can lower firms' costs. A third reason for the greater economic efficiency of larger cities is their lower transaction costs. From the production standpoint, lower costs stem from a closer matching between workers skills and job requirements, which reduces search costs for workers with differentiated skills and firms with differentiated labour demand. Lower transaction costs in the larger cities also include lower search costs for consumers as a result of retail trade clustering.

The industrial dimension can thus be classified in terms of economies of specialization (agglomeration within individual industrial sectors) and economies of diversification (the clustering of different industrial sectors). In the first case, the agglomeration generates Marshall-Arrow-Romer type externalities, or economies of specialization. Firms benefit from a clustered labour market, which would minimize transaction and communication costs for firms in the same industry. In the second case, the agglomeration of different industrial sectors generates diversity, which also encourages the fertilization of new ideas. The notion that industrial diversity directly contributes to agglomeration economies stems from Jacobs (1969), which are known as Jacobs-Porter type externalities, or economies of diversification.

The effects of agglomeration economies on productivity and economic growth have been the 
subject of several empirical studies. Henderson (1986), for example, considers the relative effects of specialization and diversification on productivity in the United States and Brazil, measuring diversification by total employment in the city, and specialization by employment in a specific industry. The results provide considerable evidence of economies of specialization but no evidence at all of diversification economies. In an analysis of the geographic scope of agglomeration economies, Rosenthal and Strange (2003) also find strong evidence for specialization.

By studying the degree of employment specialization in the cities, measured as the share of employment in a specific industry, Henderson, Kuncoro and Turner (1995) analyse the effects of specialization on the growth of eight industries, of which five were classified as mature and three as high-tech. While in the latter group specialization did not have a positive effect on growth, there was an observable positive effect in the mature group.

These authors also analyse the importance of diversity for growth and, in this case, found a positive effect for high-tech industries. Rosenthal and Strange (2003) use a diversity measure based on a HerfindahlHirschman index (HHI), which finds that diversity affects the emergence of new enterprises. Wheaton and Lewis (2002) identify a wage premium in relatively more specialized cities and a higher concentration of labour in a given industry. This result reflects the fact that labour displays strong location economies and the existence of sharp increases in specialization.
Galinari and others (2007) investigate the presence of agglomeration economies in urban settings in Brazil, and how these affect the country's urban-industrial wages. They find that these were not sufficient to mitigate wage heterogeneity between Brazil's different regions, despite the far-reaching institutional changes introduced in the 1990s. Higher levels of human capital and industrial concentration had positive and significant effects in explaining the wage level, whereas specialization had a negative and also significant effect. The latter result is treated with caution by the authors, because, in the case of Brazil, a high level of specialization cannot be seen as indicating the existence of competitive and cooperative structures that would help generate economies of specialization.

The repercussions of agglomeration economies are also reflected in both the size and the heterogeneity of cities, as analysed in the models of Abdel-Rahman (1988) and Fujita (1988). As noted above, economies of scale provide the main rationale for the existence of cities. Nonetheless, the economies obtained from shared production and consumption inputs and lower transaction costs are greater when economic activities are more diverse. A larger city will have a larger variety of consumer goods and production inputs. As greater variety increases utility and output, the larger cities are more productive and the welfare of their inhabitants increases with size. This result is holds true both for monopolistic enterprises and those operating under perfect competition (Quigley, 1998).

\section{III}

\section{Description of the data}

This work is based on the Annual Social Information Report (Relação Anual de Informações Sociais) published by the Ministry of Labour and Employment (RAIS/ MTE), which covers the entire country and contains data on the employing establishment and employee, based on formal employment contracts signed in a given base year. ${ }^{3}$

\footnotetext{
3 This section is based on Identificação, mapeamento e caracterização estrutural de arranjos produtivos locais no Brasil published by the Institute for Applied Economic Research (IPEA), coordinated by Wilson Suzigan (IPEA, 1996).
}

The employment data used relate to the number of jobs in the categories breakdown at the municipal level, by type of economic activity - the two-digit level of the National Classification of Economic Activities (CNAE). Data on average wages were related to minimum wages in the cities in question. Data on the real minimum wage in the years studied were obtained from the Inter-Union Department of Statistics and Socioeconomic Research (DIEESE), whereas data on education describe the number of workers with basic, secondary and higher education as a percentage of all workers in the city. 
The main advantage of the RAIS/MTE database is the high level of sector and geographic breakdown of the data, which makes it possible to obtain and directly process disaggregated data down to the municipal level and in sector terms. It is also highly uniform, which makes it possible to compare the distribution of economic activity sectors through time.

Nonetheless, RAIS/MTE also has some defects. The first of these concerns its coverage, because it only includes formalized contractual relations and thus excludes informal workers, thereby generating a significant bias with respect to the real labour market. A second problem stems from the use of self-classification by the firms themselves in primary data collection, since the collecting institution does not check whether the data reported correspond to reality. Self-classification may have considerable effects in cases of firms with than one plant, whose representatives report the volume of employment in a given productive unit, generally the headquarters, and firms with more than one product that are classified only according to activity corresponding to their main product. The final defect stems from the declaratory nature of the RAIS, which may cause distortions in the analysis of small firms or less developed regions where the number of non-declarants is higher.

This article used RAIS/MTE employment data for 1997 and 2007. The universe of analysis was defined on two different levels, according to the work proposal and characteristics of the RAIS database. From the geographic standpoint, urban municipalities or medium-sized and large cities were used, defined as those with over 50,000 inhabitants in the 2000 IBGE Census. This involves 524 cities from all Brazilian states, representing $64 \%$ of the population according to the aforementioned census. Economic activities were classified according to the manufacturing industry sectors at the CNAE/95 two-digit level. These sectors correspond to divisions 15-37, as defined in table 1.

Data on GDP per capita and the distance of the various municipalities from the state capital was obtained from the IPEA regional database (Ipeadata), while population data were obtained from the IBGE. ${ }^{4}$

\footnotetext{
4 The data are available online at www.ipeadata.gov.br and http:// www.ibge.gov.br/home/estatistica/populacao/.
}

Brazil: National Classification of Economic Activities (CNAE), divisions 15-37, 1995

\begin{tabular}{ll}
\hline Division 15 & Manufacture of food products and beverages \\
Division 16 & Manufacture of tobacco products \\
Division 17 & Manufacture of textile products \\
Division 18 & Manufacture of garments and accessories \\
Division 19 & Preparation of leathers and manufacture of leather artefacts and articles \\
Division 20 & Manufacture of wood products \\
Division 21 & Manufacture of wood pulp, paper and paper products \\
Division 22 & Publishing, printing and reproduction of recordings \\
Division 23 & Manufacture of coal, oil refining, manufacture of fuels \\
Division 24 & Manufacture of chemical products \\
Division 25 & Manufacture of rubber and plastic products \\
Division 26 & Manufacture of non-metallic mineral products \\
Division 27 & Basic metallurgy \\
Division 28 & Manufacture of metal products - except machinery and equipment \\
Division 29 & Manufacture of machinery and equipment \\
Division 30 & Manufacture of office machinery and computer hardware \\
Division 31 & Manufacture of electrical machinery, apparatus and materials \\
Division 32 & Manufacture of electronic material and apparatus and communication equipment \\
Division 33 & Manufacture of instrument equipment for medical-hospital uses \\
Division 34 & Manufacture and assembly of automobiles, tow-trucks and chassis \\
Division 35 & Manufacture of other transport equipment \\
Division 36 & Manufacture of furniture and various industries \\
Division 37 & Recycling
\end{tabular}

Source: Ministry of Labour and Employment (MTE) of Brazil. 


\section{IV}

\section{Industrial diversity and specialization in Brazil}

An analysis of manufacturing-industry specialization and diversity in the cities requires adequate measurement tools. Authors such as Glaeser and others (1992), and Henderson, Kuncoro and Turner (1995) measure industry scope as the share of employment in a given industry. The simplest way to measure a city's specialization in a given sector is to quantify the share of each sector in local employment. If $s_{i j}$ is the share of industry $j$ in city $i$, the following specialization index (IE) can be defined:

$$
I E_{i}=\max _{j}\left(s_{i j}\right)
$$

As some sectors absorb large percentages of local employment, it is better to use a relative measure of specialization, dividing the local index by the sector's percentage share of national employment. The relative specialization index (IER) is:

$$
I E R_{i}=\max _{j}\left(s_{i j} / s_{j}\right)
$$

where $s_{i j}$ the share of industry $j$ in national employment.

A common measure of diversity is the inverse Herfindahl-Hirschman index, which is obtained from the ratio between one and the sum of the squares of the sector's share in local employment. The diversification index (ID) is therefore given as:

$$
I D_{i}=1 / \sum_{j} s_{i j}^{2}
$$

This measure needs to be corrected for differences in the sector employment shares at the national level:

$$
I D R_{i}=1 / \sum_{j}\left|s_{i j}-s_{j}\right|
$$

The relative diversification index (IDR) will be higher when the distribution of activities in the city matches the pattern of diversity in $\neq$ the economy nationwide. Measured in this way, specialization and diversification are not really opposites, and a city may be considered specialized in a given sector but diversified in sector-terms generally.

\section{Specialization in Brazilian cities}

Table 2 lists the most and least specialized cities in Brazil in 2007. In the case of the least specialized, the highest IER among all sectors is shown. In the case of the most specialized cities, those specializing in sectors that depend on natural resources, such as tobacco, coexist with others specializing in sectors that make intensive use of capital goods such as office machinery and computer hardware, oil and other transport equipment.

Another characteristic of specialization is the geographic location of the most highly specialized municipalities: 53 of the 100 most specialized are located in the north and north-eastern regions of Brazil, which in turn contain $35 \%$ of the country's urban municipalities. At the other extreme are cities with low IERs, where no sector has an employment share greater than 2.3 times the national percentage for that sector. In the three least specialized cities (in the food products and beverages sector) the degree of specialization is high, but relative specialization is low because the specialization pattern is similar to that of the country as a whole (in the case of Viamão, for example, that sector represents $47 \%$ of the city's employment).

\section{Diversification}

The most and least industrially diversified cities are shown below. Six of the 10 most diversified are state capitals. Of the 25 least diversified cities, 20 belong to the north and northeastern regions. The five least diversified are shown in table 3. Only one of these, Angra dos Reis, which is among the most specialized, is also one of the least diversified. The most diversified cities (Belo Horizonte, Cuiabá, Recife, Salvador and Rio de Janeiro) do not have high specialization indices in any of the sectors considered.

One of the features of diversification highlighted in the literature is its relation to city size (Duranton and Puga, 2000): the largest cities tend to be the most diversified. Figure 1 shows the relationship between city size, measured by total employment, and its relative diversification index (IDR), as described above. As also noted in literature, this shows that 
TABLE 2

Brazil: Most and least specialized cities, 2007

\begin{tabular}{|c|c|c|c|}
\hline Position & City & Sector & $\begin{array}{c}\text { Relative specialization } \\
\text { index (IER) }\end{array}$ \\
\hline 1 & Poá (SP) & Textile products & 458.70 \\
\hline 2 & Santa Cruz do Sul (RS) & Tobacco products & 168.65 \\
\hline 3 & Venâncio Aires (RS) & Tobacco products & 94.36 \\
\hline 4 & Angra dos Reis (RJ) & Other transport equipment & 72.30 \\
\hline 5 & Lagarto (SE) & Tobacco products & 71.48 \\
\hline 6 & Ilhéus (BA) & Office machinery and computer hardware & 67.15 \\
\hline 7 & Vitória de Santo Antão (PE) & Coal, oil refining, manufacture of fuels & 47.52 \\
\hline 8 & Piedade (SP) & Office machinery and computer hardware & 43.27 \\
\hline 9 & Niterói (RJ) & Other transport equipment & 40.81 \\
\hline 10 & Patos (PB) & Tobacco products & 37.31 \\
\hline$\cdots \cdots$ & .............. & 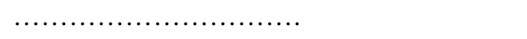 & $\ldots$ \\
\hline 521 & Catanduva (SP) & Machinery and equipment & 2.35 \\
\hline 522 & Guarulhos (SP) & Rubber and plastic products & 2.31 \\
\hline 523 & Viamão (RS) & Food products and beverages & 2.27 \\
\hline 524 & Rondonópolis (MT) & Food products and beverages & 2.18 \\
\hline 525 & Mossoró (RN) & Food products and beverages & 1.96 \\
\hline
\end{tabular}

Source: Prepared by the authors on the basis of Relatório Anual de Informações Sociais published by the Ministry of Labour and Employment (RAIS/MTE), 2007.

SP: São Paulo. RS: Rio Grande do Sul. RJ: Rio de Janeiro. SE: Sergipe. BA: Bahia. PE: Pernambuco. PB: Paraíba. MT: Mato Grosso. RN: Rio Grande do Norte.

TABLE 3

Brazil: Most and least diversified cities, 2007

\begin{tabular}{rlc}
\hline Position & City & $\begin{array}{c}\text { Relative } \\
\text { diversification } \\
\text { index (IDR) }\end{array}$ \\
\hline 1 & Belo Horizonte (MG) & 2.31 \\
2 & Feira de Santana (BA) & 2.25 \\
3 & Londrina (PR) & 2.16 \\
4 & Cuiabá (MT) & 2.14 \\
5 & Recife (PE) & 2.10 \\
6 & Salvador (BA) & 2.01 \\
7 & Cascavel (PR) & 1.99 \\
8 & Rio de Janeiro (RJ) & 1.98 \\
9 & Campo Grande (MS) & 1.89 \\
10 & Ribeirão Preto (SP) & 1.84 \\
$\ldots \ldots$. & .................................................. & $\ldots \ldots .$. \\
521 & Santa Cruz do Capibaribe (PE) & 0.61 \\
522 & Russas (CE) & 0.60 \\
523 & Paragominas (PA) & 0.58 \\
524 & Ipirá (BA) & 0.55 \\
525 & Angra dos Reis (RJ) & 0.55 \\
\hline
\end{tabular}

Source: Prepared by the authors on the basis of Relatório Anual de Informações Sociais published by the Ministry of Labour and Employment (RAIS/MTE), 2007.

MG: Minas Gerais. BA: Bahia. PR: Paraná. MT: Mato Grosso. PE: Pernanbuco. RJ: Rio de Janeiro. MS: Mato Grosso do Sul. SP: São Paulo. CE: Ceará. PA: Pará. industrial variety or heterogeneity is a rationale for existence of larger urban areas, which can obtain greater advantages from economies of scale and indivisibilities in production.

Although there is a positive correlation between city size and the $I D R$, it is not very strong $(0.58)$. This may be explained by the fact that a large component of employment in most cities is in activities producing non-tradable goods. Another factor that affects the result is the existence of large cities that are considerably specialized for their size, including Manaus (specialized in the manufacture of electronic material and apparatus and computer hardware and equipment), along with small, highly diversified cities (Itajaí, São José and Palhoça in Santa Catarina). This finding is consistent with other empirical tests showing how cities at the top of the size ranking tend to have a diversified industrial structure, whereas the others are more specialized as size decreases (AbdelRahman and Anas, 2004). 


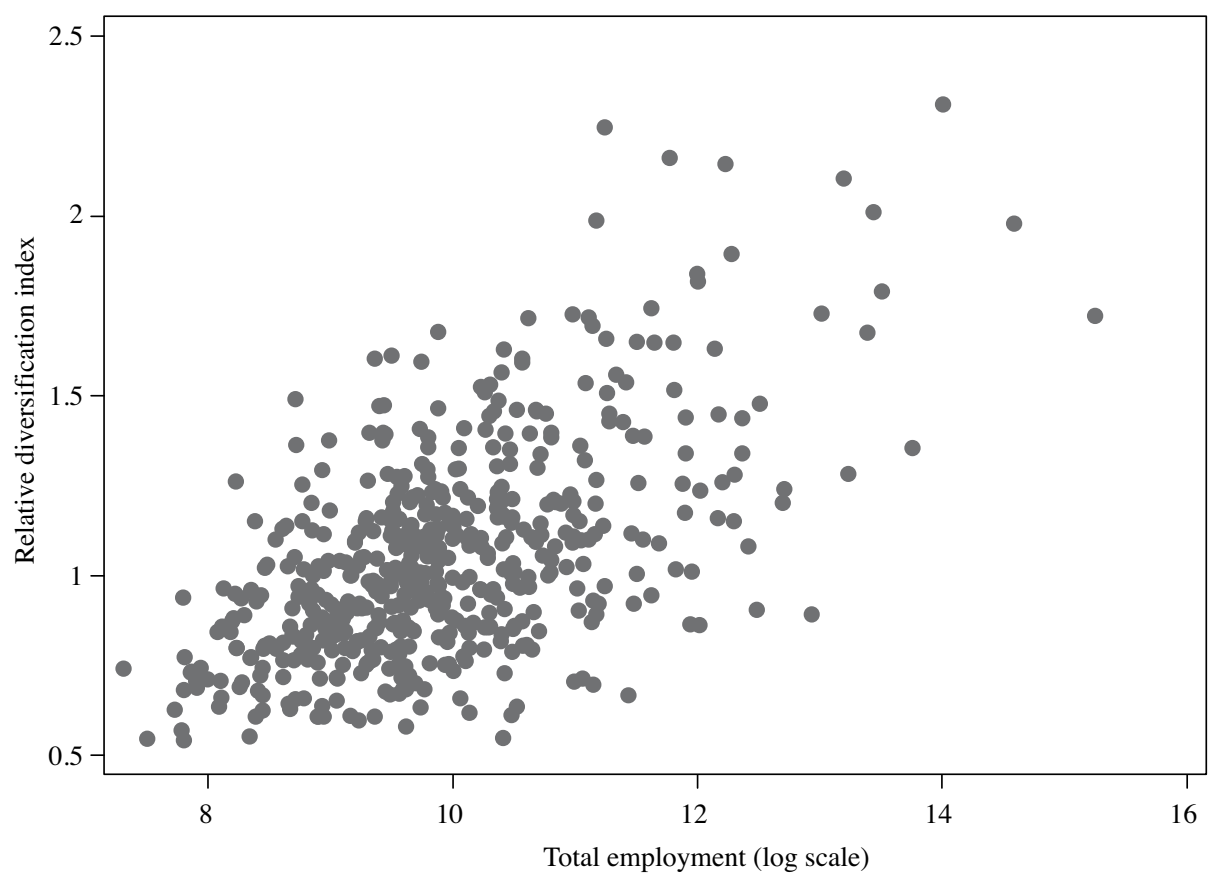

Source: Prepared by the authors on the basis of Relatório Anual de Informações Sociais published by the Ministry of Labour and Employment (RAIS/MTE), 2007.

\section{Grouping of Brazilian municipalities by size, specialization and diversification}

Cluster analysis was used to identify the specific characteristics of homogeneous components within a population of heterogeneous municipalities, and to define groups on the basis of multivariate data, namely indices of specialization, diversification and city size, measured according to the total employment in the city.

The cluster analysis consists of two steps: (i) select the data grouping algorithm; and (ii) decide on a criterion for choosing the optimal number of groups. With respect to the first of these, the k-means method, which consists of a grouping algorithm proposed by MacQueen in 1967, is the best-known and most widely applied. This algorithm requires the data to consist of numerical variables, since part of the process involves calculating means. The k-means method is a non-hierarchical technique for grouping elements through a more flexible process, in the sense that an item assigned initially to a given group can be reassigned several times during the grouping process. Specifically, the k-means algorithm - given a set of $n$ points in d-dimensional real space $\left(R^{d}\right)$ and an integer $k$ - consists of defining the $k$ sets of points in $R^{d}$ that minimizes the mean-square distance of each point from the centroid of the set closest to it.

This procedure consists of assigning each observation to the group whose centroid is most similar to the vector of observed values. In simplified form, the procedure has three steps: (i) divide the elements into $k$ initial clusters; (ii) assign each element to the 
cluster whose centroid is closest and recalculate the centroid of the cluster that received the element and that of the cluster that lost it; and (iii) repeat the second step until no new arrangement of the elements is possible.

In non-hierarchical procedures, it is necessary to specify the initial number of groups and choose the optimal number of groups, using an appropriate criterion. The criterion used is that proposed by Calinski and Harabasz (1974), known as the $\mathrm{CH}$ index. This procedure assumes the number of groups, $k$, as given. The database is then divided among the $k$ groups, and an equitable distribution of the points is made at random in each of the groups formed. Following the division into $k$ groups, the group to which each point belongs is verified, on the basis of the distance between the point at the centre of each group. The group with the smallest distance receives that point. When a point changes group, its centre is recalculated. To form the groups, the algorithm groups the elements according to their proximity, based on two premises: maximize the similarity between the elements of the same cluster and maximize dissimilarity between different clusters. To select the most appropriate clusters within the k-means technique based on an object's attributes matrix, the authors propose use the $\mathrm{CH}$ index, defined as follows:

$$
C H=\frac{B^{*}(n-k)}{W^{*}(k-1)}
$$

where $n$ is the number of points and $k$ is the number of groups. The matrices $B$ and $W$ are obtained using the following formulas:

$$
W=\sum_{i=1}^{K} \sum_{j=1}^{n_{i}}\left(X_{i j}-\bar{X}_{i}\right)^{2}
$$

where the value of $W$ is the sum of the squares of the distances from the points to the centre of the groups to which they belong, $X_{i j}$ is the $j$ th point of group $i, \bar{X}_{i}$ is the centre of the group (measured from the points to the centre of the group) and $n_{i}$ is the number of points in group $i$.

$$
T=\sum_{i=1}^{K} \sum_{j=1}^{n}\left(X_{i j}-\bar{X}\right)^{2}
$$

$T$ is the sum of the squares of the differences from each point of the entire database and the centre of the entire base, represented by $\bar{X}$.

$$
B=T-W \sum_{i=1}^{k} n_{i}\left(\bar{X}_{i}-\bar{X}\right)^{2}
$$

where the value of $B$ can be obtained from the difference between $T$ and $W$, which is the sum of the products between the number of points in the entire database and the squares of the differences between the centre of the entire base and the centre of each group.

The Calinski-Harabasz model selection heuristic consists of two steps: (i) calculate the value of the $\mathrm{CH}$ index for all group solutions from which it is desired to choose; and (ii) select the solution with the highest $\mathrm{CH}$ index.

Taking account of the three variables indicated, application of the Calinski-Harabasz criterion made it possible to establish an optimal number of two groups (see table 4). With these two clusters, the pseudo-F statistic of this criterion has a maximum value of 407.66 .

TABLE 4

Calinski-Harabasz criterion to determine the optimal number of groups

\begin{tabular}{cc}
\hline Number of groups & Pseudo-F Calinski-Harabasz \\
\hline 2 & 407.66 \\
3 & 369.39 \\
4 & 363.39 \\
5 & 332.32 \\
\hline
\end{tabular}

Source: Prepared by the authors on the basis of the results obtained from the k-means cluster analysis.

Table 5 shows the characteristics of the clusters obtained. Cluster 1 has the highest weight, since it contains 355 of the 524 municipalities in the sample. The remaining 169 municipalities correspond to cluster 2 . Cluster 1 has the highest IER and the lowest IDR, and its size with respect to total employment in the city is 10 times less than that of cluster 2. Nonetheless, the characteristics of cluster 2 show that even when there is strong evidence of the existence of a clear and positive relation between diversification, specialization and city size, this is not the case in Brazil owing to the heterogeneity of its cities. This cluster contains the large urban centres of the state of São Paulo and all state capitals, along with smaller cities that have an industrialization pattern that is similar to that of these cities, including Simões Filho (Bahia), Araras (São Paulo), Colombo (Paraná), Pouso Alegre (Minas Gerais), Várzea Grande (Mato Grosso), and other cities 
TABLE 5

Characteristics of the clusters

\begin{tabular}{cccccr}
\hline Cluster & Frequency & Weight & Relative diversification index (IDR) & Relative specialization index (IER) & Size \\
\hline 1 & 355 & 67.75 & 0.95 & 7.57 & 13182 \\
2 & 169 & 32.25 & 1.26 & 5.81 & 149266 \\
\hline
\end{tabular}

Source: Prepared by the authors on the basis of the results obtained from the k-means cluster analysis.

which, although relatively larger, display a low-level diversification and a high degree of specialization, such as Chapecó (Santa Catarina).

The cluster analysis thus confirms the existence of heterogeneity, and the fact that this is not explained only by city size - measured by total employment but also by the industrial characteristics of the city in question. This requires an appropriate methodology to capture the wealth of heterogeneous data. The following section defines and estimates a finitemixture regression and another that takes account of the quantiles within the distribution, thereby making the heterogeneity identified by the cluster analysis explicit.

\section{VI}

\section{Finite-mixtures regression models}

This section discusses the problem of estimating a regression model assuming the data are generated from a finite-mixture density function, with different parameter values for each component (or group) within the distribution. As estimation based on the simple probability density hypothesis can generate biased parameters, it is better to model the statistical distribution from a mixture of other distributions, thereby controlling for the heterogeneity of the sample.

The cluster analysis showed that the municipalities were heterogeneous, so the data need special treatment. To strengthen that justification, the Bayesian information criterion was used to identify the model that best fit the data, comparing ordinary least squares (OLS) (one component) with different finite-mixture models (two and three components). ${ }^{5}$

Traditional statistical analyses cannot explain unobserved heterogeneity - in this case, individual differences in the behaviour of municipalities in terms of the average wage in relation to their industrialization pattern. The finite-mixtures model makes it possible to estimate the effect of specialization and diversification on the average wage, encompassing groups of municipalities that respond differently than the average.

\footnotetext{
${ }^{5}$ If the three-components model is rejected, it is not necessary to analyse models with a larger number of groups.
}

How do municipalities react to the type of specialization and diversification they display? Do they react in one way only, or in different ways? If they react differently, how can their behaviour be studied? Can municipalities be classified in groups within which inferences can be made on common behaviour? These questions show that the argument on heterogeneity between municipalities is crucial for understanding the effects of the type of industrialization (specialized/ diversified) on the level of the average wage.

The most common way to deal with heterogeneity in panel data is to include dummy variables to control for differences between average wages; but this does not control for differences in the marginal effects of the regressors. An alternative is to find groups of observations for which the process is similar; but this requires choosing average wage levels a priori, and even then municipalities with different industrial integration processes can coexist in the same group.

In contrast to these approaches, this article proposes a methodology based on the data to estimate multiple processes of average wage growth. In the models estimated, the municipalities are chosen on the basis of similarities in their distributions conditional on the average wage growth process.

Applications of the finite mixtures model in econometrics include the seminal papers by Heckman and Singer (1984) (on the labour market); Deb and Trivedi (1997); and Bago D’Uva (2006) (on health 
economics); Alfo, Trovato and Waldman (2008); Deb and others (2009).

In the context of the foregoing discussion, use of the normally distributed finite-mixtures model is a tool that uses the data on industrial specialization and diversification variables, to determine different intensities of response in the endogenous variable (average worker income) without having to separate the groups arbitrarily (for example, large, mediumsized and small municipalities).

The estimation strategy involves evaluating the number of groups that the data can support. ${ }^{6}$ In that way, it is verified whether the data fit a one-component regression (OLS) better, or whether it is advisable to apply a finite mixtures regression -in other words if the heterogeneity of the data justifies a differentiated methodology, taking different groups into account. If so, we must also decide how many groups the data support within the finite mixtures regression. The Schwartz information criterion (BIC) is used to choose the best number of groups for the data and is obtained as follows:

$$
B I C=-2 \log (L)+K \log (N)
$$

Where $L, K$ and $N$ are the logarithms of maximum likelihood, number of parameters and number of observations, respectively. The model chosen has the smallest BIC value, considering that in some cases the additional components may simply be displaying outlier data points.

The finite-mixtures regression model is defined from a family of parametric density functions, as explained below (Khalili and Chen, 2007). Formally, $Y$ is the response variable of interest; $x=\left(x_{1}, x_{2}, \ldots, x_{p}\right)^{\tau}$ is the vector of co-variables affecting $Y ; \Omega=\{f(y ; \theta, \phi) ;(\theta, \phi) \in \Theta \times(0, \infty)\}$ is a family of parametric density functions of $\mathrm{Y}$ in

\footnotetext{
6 To confirm the heterogeneous nature of relations between agglomeration and productivity economies, a quantile regression model was also estimated. In this technique, apart from not requiring the basic minimum-squares assumption of homoscedastic (or guassian) errors, the information is greater, because it makes it possible to estimate the conditional distribution of the dependent variable through the distribution quantiles. A regression can be obtained for each quantile of interest, compared to ordinary least squares (OLS), which only provides the mean of the distribution. The regression results confirm the heterogeneity of the data. Only the results of the finite samples regression are presented, because this method deals better with the heterogeneity between groups characterized by lack of linearity and not by a continuous process of alterations between the variables of interest.
}

relation to a finite mixture, in which $\Theta \subset \Re$ y $f$ is the dispersion parameter. Accordingly, $(x, Y)$ follows a finite-mixtures regression model of order $K$ if the conditional density function of $Y$ given $x$ has the following form:

$$
f(y ; x, \Psi)=\sum_{k=1}^{K} \pi_{k} f\left(y ; 0_{k}(x), \phi_{k}\right)
$$

with $\quad 0_{k}(x)=h\left(x^{\tau} \beta_{k}\right), k=1,2, \ldots ., K \quad$ and for $\Psi=\left(\beta_{1}, \beta_{2}, \ldots, \phi, \pi\right)$ with $\beta_{k}=\left(\beta_{k 1}, \beta_{k 2}, \ldots, \beta_{k P}\right)^{\tau}$, $\phi=\left(\phi_{1}, \phi_{2}, \ldots, \phi_{k}\right)^{\tau}, \pi=\left(\pi_{1}, \pi_{2}, \ldots, \pi_{K-1}\right)^{\tau} \mathrm{such}$ that $\pi_{k}>0$ is $\sum_{k=1}^{K} \pi_{k}=1$

The density function may take different parametric forms, including the binomial, normal and Poisson distributions, identifiable under certain conditions (Titterington, Smith, Markov, 1985). In this case, the normal function was used.

The finite mixtures regression model to be estimated can be described as follows:

$$
\begin{gathered}
y_{i k}=\alpha_{k}+\beta_{1 k} i e r_{i k}+\beta_{2 k} i d r_{i k}+ \\
\beta_{3 k} d i s t_{i k}+\beta_{4 k} t^{t a m} m_{i k}+\beta_{5 k} e d u_{i k}+u_{i k}
\end{gathered}
$$

where $y_{i k}$ is the average income of a worker in municipality $i$ in component $k ; \alpha_{\mathrm{k}}$ is the intercept for component $k$; ier $i k$ is the logarithm of the relative specialization index for municipality $i$ in component $k ; i e r_{i k}$ is the logarithm of the relative diversification index for municipality $i$ in component $k$; dist $t_{i k}$ is the logarithm of the distance of the city from the state capital; $\operatorname{tam}_{i k}$ is city size, using the logarithm of the population density as a proxy; $e d u_{i k}$ is the number of workers with basic, secondary and higher education as a percentage of the total number of workers in the city; $u_{i k}$ is the error term, whose variance $\sigma_{i k}^{2}$ is assumed to be normal and homoscedastic, within the components, but possibly heteroscedastic between components.

Table 6 shows the goodness of fit criterion $(B I C)$ for the models: (i) of one component, which corresponds to an OLS estimation (considering robust errors); (ii) two components; and (iii) three components (which corresponds to estimations using a finite mixtures model (FMM)). It should be remembered that the lower the BIC value, the worse the data fit the tested model. 
TABLE 6

Schwartz information criteria (BIC) for regressions with different numbers of components

\begin{tabular}{lc}
\hline Model & BIC \\
\hline Ordinary least squares - one component & 755.70 \\
Finite mixtures model - two components & 606.13 \\
Finite mixtures model - three components & 622.99 \\
\hline
\end{tabular}

Source: Prepared by the authors on the basis of Relatório Anual de Informações Sociais published by the Ministry of Labour and Employment (RAIS/MTE), 2007, and Ipeadata of the Institute of Applied Economic Research (IPEA).

As the results in table 6 show, the BIC information criterion determines the choice of two components. Another criterion confirming this result is that the third component accounts for just $1 \%$ of the municipalities, and, apart from being unrepresentative, it does not change the estimated coefficients. This result also agrees with the number of groups estimated in the cluster analysis using the Calinski-Harabasz criterion.

The results show that municipal heterogeneity is bimodal when using these variables to estimate the regression, which confirms the findings of other studies. For example, Laurini, Andrade and Pereira (2003) find the existence of two income groups among Brazilian municipalities in the period 1970-1996: a low-income group, consisting of municipalities in the north and northeast regions, and a highincome group, consisting of municipalities in the centre-east, south and southeast regions. Chein, Lemos and Assunção (2007) makes progress in the study of unequal development between regions considered to be homogeneous. These authors construct vectors of attributes based on factorial analysis for different territorial units. The results show a high concentration of excluded zones in the north and northeast, and the existence of zones displaying another dynamic within the same space. Territorial spaces in the most developed macroregions are also not homogeneous, because they also contain less developed regions. The finite-mixtures methodology shows that even within the north and northeast regions, there are some municipalities with differentiated characteristics, while other cities belonging to high-income regions are part of the low-productivity group, as analysed below.

The results shown in table 7 refer to the regression with the real average wage per worker in each municipality as the dependent variable. Economies of diversification and specialization are positive in all cases.
The group defined by the lowest real average wage per worker (group 1) includes cities in the north and northeast regions, whereas Minas Gerais is the state with most cities in this group among the states of the south and southeast regions.

Group 2 corresponds to the higher real wage per worker $(1,300$ reais, considering the value of the minimum wage in 2007). This group's relative specialization coefficient is higher than its diversification coefficient, and there is also a positive and significant education effect. In the case of group 1, economies of diversification are large and significant, whereas the coefficient for workers with formal education as a percentage of total workers is not significant.

It is interesting to note that the significance of specialization and diversification is reversed in the two groups: diversification is important when incomes are lower, whereas specialization is significant in the higher-income group. This might be explained by the fact that specialization in the lower-income groups probably occurs in activities with little technological content or capacity to generate learning. The incorporation of new activities would thus involve a structural shift towards more skill-intensive activities. In contrast, when incomes are higher, activities are likely to have a larger knowledge content, and the exploitation of higher returns through specialization has greater repercussions.

The bimodality found in other studies is also confirmed, generally linked to the dichotomy between the north-north east and south-south-east regions of Brazil. Nonetheless, this dichotomy breaks down for cities that belong to a poor or wealthy region but do not display the same pattern as the region generally. For example, in the southeastern state of Minas Gerais, there are several cities corresponding in 1 (relatively poorer), while some cities in the north and northeast regions (particularly state capitals and other cities such as Camaçari, Coari and Manacapuru), belong to the relatively wealthier group 2 .

City size also has the expected sign. Larger size is associated with higher real wages, because of the exploitation of both types of agglomeration economies, either through more numerous industrial linkages (economies of diversification) or more efficient search and matching in the labour market, since larger scale encourages workers to specialize in certain types of activity (specialization economies).

The education coefficients are different between the two groups. In the first case, the number of formally educated workers (as a percentage of all workers) does 
TABLE 7

Brazil: Estimation of finite-mixtures regression

for two groups of municipalities, 1997 and 2007

\begin{tabular}{|c|c|c|c|}
\hline Dependent variable: real average worker incomes ( y ) & OLS & Group 1 & Group 2 \\
\hline Intercept & $\begin{array}{c}3.5493^{\mathrm{a}} \\
(0.0641)\end{array}$ & $\begin{array}{c}4.4964^{\mathrm{a}} \\
(0.0964)\end{array}$ & $\begin{array}{r}3.2651^{\mathrm{a}} \\
(0.0959)\end{array}$ \\
\hline Relative specialization index (IER) & $\begin{array}{r}0.0386^{\mathrm{a}} \\
(0.0167)\end{array}$ & $\begin{array}{c}0.0371 \\
(0.0257)\end{array}$ & $\begin{array}{r}0.0646^{\mathrm{a}} \\
(0.0264)\end{array}$ \\
\hline Relative diversification index (IDR) & $\begin{array}{c}0.2303^{\mathrm{a}} \\
(0.0483)\end{array}$ & $\begin{array}{c}0.4730^{\mathrm{a}} \\
(0.0602)\end{array}$ & $\begin{array}{c}0.0073 \\
(0.0047)\end{array}$ \\
\hline Distance from the capital & $\begin{array}{l}-0.0420^{\mathrm{a}} \\
(0.0061)\end{array}$ & $\begin{array}{l}-0.0510^{\mathrm{a}} \\
(0.0094)\end{array}$ & $\begin{array}{l}-0.0494^{\mathrm{a}} \\
(0.0108)\end{array}$ \\
\hline Education & $\begin{array}{r}1.8724^{\mathrm{a}} \\
(0.0651)\end{array}$ & $\begin{array}{c}0.1145 \\
(0.1094)\end{array}$ & $\begin{array}{r}2.4574^{\mathrm{a}} \\
(0.0838)\end{array}$ \\
\hline City size & $\begin{array}{c}0.0203^{\mathrm{a}} \\
(0.0057)\end{array}$ & $\begin{array}{c}0.0135^{\mathrm{b}} \\
(0.0075)\end{array}$ & $\begin{array}{r}0.0184^{\mathrm{c}} \\
(0.0084)\end{array}$ \\
\hline Proportion of the sample (percentage) & 100.00 & 46.94 & 53.05 \\
\hline $\mathrm{R}^{2}$ & 0.5872 & & \\
\hline Mean of $y$ (in reais) & 1150.40 & 991.80 & 1295.80 \\
\hline Number of observations & 1039 & & 1039 \\
\hline
\end{tabular}

Source: Prepared by the authors on the basis of Relatório Anual de Informações Sociais published by the Ministry of Labour and Employment (RAIS/MTE), 2007, and Ipeadata of the Institute of Applied Economic Research (IPEA).

Note: Robust standard errors (in parentheses)

a Significant at the $1 \%$ level.

b Significant at the $10 \%$ level.

Significant at the $5 \%$ level.

OLS: Ordinary least squares.

not have a significant influence on the wage paid. In contrast, in the second group of relatively better paid workers, the coefficient is highly significant $(\mathrm{t}=29.32)$. This would confirm that investment in education is a way to increase labour productivity, thereby also generating a virtuous circle of higher productivity - higher returns - greater consumption - greater local development - greater national development. Nonetheless, for these investments to take place, physical capital is needed to complement human capital, and thus encourage workers to remain in the municipality after they have been trained. The lack of statistical significance in the first group could reflect a low level of complementarity for higherskilled workers, which would cause them to migrate to regions offering higher levels of complementarity and, therefore, greater opportunities.

The results of the OLS estimation confirm the findings of Galinari and others (2007), who suggest that cities with high levels of industrial concentration but no clear productive specialization are subject to externalities of scale of urbanization, but their specialization economies are non-existent or very weak. According to these authors, the latter result suggests that the existence of a cluster of firms in the same branch of activity in a given locality is not a sufficient condition to generate external economies. Although this is true for $60 \%$ of the municipalities in the sample used in this article, the finite-mixtures estimation finds positive and significant specialization economies in explaining the level of average income of workers and GDP per capita in the other municipalities. Thus, an estimation method that controls for the diversity of the sample could help identify the influences of variables that are not captured by other methods.

The existence of economies of specialization confirms the findings of Wheaton and Lewis (2002), which show that employment displays a sharp gains in specialization. Those authors also find little evidence of economies of diversification, which is the result in our group 2 that corresponds to the higher real average wage per worker. This group contains large metropolis such as São Paulo, Rio de Janeiro, Belo Horizonte, Porto Alegre, Curitiba and other smaller capitals that were growing fast in the period being studied, such as 
Palmas (Tocantins) and Rio Branco (Acre), but also medium-sized cities, where strengthening is reflected in the process of de-concentration of production and population in national territory, as shown in the work of IPEA/IBGE/UNICAMP (2002). This group includes the large cities of São Paulo, Florianópolis (Santa Catarina), Maringá (Paraná), Londrina (Paraná), Canoas (Rio Grande do Sul), Caxias do Sul (Rio Grande do Sul) and others. The group also contains oil cities such as Macaé (Rio de Janeiro) and Coari (Amazonas), and others displaying productive integration between industry and agriculture, such as Uberlândia (Minas Gerais), São José do Rio Preto (São Paulo) and Rondonópolis (Mato Grosso). ${ }^{7}$

In short, two different patterns were found in the relation between agglomeration economies and workers' wages, for the 524 municipalities in the sample. The first group corresponds to municipalities with lower average wages, in which specialization economies are not very important. This would suggest the existence of unsophisticated productive clusters and weak linkages, which are compensated by exploiting economies of diversification. These

\footnotetext{
${ }^{7}$ For an analysis of this integration see Lemos and others (2003).
}

\section{VII}

\section{Final comments}

The main purpose of this article was to analyse the relation between agglomeration economies of the Marshall-Arrow-Romer type (economies of location or specialization) and the Jacobs-Porter type (economies of urbanization or diversification), and labour productivity in the cities as measured by the average worker wage. To that end, the article firstly described the characteristics of the relative specialization and diversification process in manufacturing industry in 524 urban municipalities in Brazil, constructing specialization and diversification measures for the years 1997 and 2007. As established in the theoretical and empirical literature, the results showed that diversification is related to city size.

Secondly, these municipalities were classified in homogeneous groups in terms of the type of industrial municipalities would fit a developing-country model. The second group consists of municipalities with higher average wages, corresponding to a developedcountry model, with positive and significant specialization economies but weak diversification economies. This result can be evaluated in the light of those produced by the Mori and Turrini (2005) model, which shows that, in the location of workers, symmetric configurations may not be stable, and regional inequality is inevitable. Relatively higherskilled workers tend to gravitate towards places with higher aggregate incomes and skills, whereas the relatively less skilled remain in the other cities. In that way, inequalities between regions are reflected in skill inequalities between individuals.

The low significance level of the relative diversification coefficient in $40 \%$ of the municipalities indicates the need to distinguish between diversification economies based on "related variety" and those based on "unrelated variety" (Frenken, Van Oort and Verburg, 2007). If there are complementarities between sectors in terms of shared skills, the externalities will produce indirect knowledge effects and subsequent growth. Such complementarities are captured through the notion of related variety (diversification), whereas no indirect knowledge effects are expected in regions where unrelated variety prevails. cluster present. For that purpose, a multivariate approach was used, jointly considering these indices and the size of the municipalities based on k-means analysis. Application of the Calinski-Harabasz criterion identified two groups, which justifies the use of a suitable methodology to capture the heterogeneity of Brazilian municipalities.

The relation between the industrial specialization and diversification indices and a productivity measure (average worker wage) was then tested empirically to ascertain the effect of agglomeration economies on development. The use of regressions that control for data heterogeneity and the differentiated influence of the explanatory variables on the dependent variable has a potential advantage compared to traditional methodologies for identifying municipalities which, 
while belonging to different states and meso- and micro-regions, display similar features in terms of the agglomeration pattern and the economic consequences thereof. Against this backdrop, regressions were estimated using finite mixtures within the distribution.

The results of the finite-mixtures regression confirm the duality that exists between the northnortheast and south-southeast regions of Brazil, which has been widely studied elsewhere. Nonetheless, this duality needs to be analysed taking account of the fact that some cities do not reflect the dynamic of the region to which they belong. This duality also has another important feature regarding the exploitation of agglomeration economies for development. The results make it possible to distinguish two municipality groups. The first contains municipalities with lower average wages, in which specialization economies are insignificant. This would point to the existence of unsophisticated productive clusters and weak linkages, offset by the exploitation of diversification economies. These municipalities would fit a developingcountry model. The second group corresponds to municipalities with high average wages, consistent with a developed-country model, with positive and significant specialization economies but weak or negative diversification economies.

The article shows that policies to promote productive deepening are more important in lowerincome cases. When the production structure is more concentrated in activities that are not knowledge intensive, improving that structure is crucial for promoting income growth. The transformation of diversification economies into specialization economies, and the engagement by municipalities in more dynamic development processes entails recognizing local productive possibilities and public policies targeted on these faster growing sectors.

Policies need to be implemented to encourage the emergence of new activities and the creation of upstream and downstream links in the productive chain. The higher-income municipalities would also benefit more from policies that strengthen specialization in already-existing dynamic activities - since they speed up progress along the learning curves. In those cases, policies to create technological and support capacities concentrated in those dynamic activities would have a more important role to play.

Industrial policy has evolved to increasingly include the interaction between variables relating technology supply and demand, stressing the relation between structural change and the role of scientific and technological institutions (both public and private). In the poorer municipalities, there is no point in providing strong support on the supply side without a parallel change in productive activities that redefines the intensity of technological demand. In the higherincome municipalities, in contrast, strengthening supply could be more important, since it would help strengthen specialization, thus overcoming existing capacity constraints in sectors that are naturally more knowledge-intensive.

(Original: Portuguese)

Bibliography

Abdel-Rahman, H. (1988), "Product differentiation, monopolistic competition and city size", Regional Science and Urban Economics, vol. 18, No. 1, Amsterdam, Elsevier.

Abdel-Rahman and A. Anas (2004), "Theories of systems of cities", Handbook of Regional and Urban Economics, J.V. Henderson and J.F. Thisse (eds.), vol. 4, Amsterdam, Elsevier.

Abdel-Rahman and M. Fujita (1990), "Product variety, Marshallian externalities and city sizes”, Journal of Regional Science, No. 30, Oxford, Blackwell Publishing.

Alfo, M., G. Trovato and R. Waldmann (2008), "Testing for country heterogeneity in growth models using a finite mixture approach", Journal of Applied Econometrics, vol. 23, No. 4, Hoboken, John Wiley \& Sons.

Anas, A. and K. Xiong (2003), "Intercity trade and the industrial diversification of cities", Journal of Urban Economics, vol. 54, No. 2, Amsterdam, Elsevier.
Bago d'Uva, T. (2006), "Latent class models for utilisation of health care", Health Economics, vol. 15, No. 4, York, Centre for Health Economics, University of York.

Baldwin, R. and P. Martin (2004), "Agglomeration and regional growth", Handbook of Regional and Urban Economics, J.V. Henderson and J.F. Thisse (eds.), Amsterdam, Elsevier.

Calinski, T. and J. Harabasz (1974), "A dendrite method for cluster analysis", Communications in Statistics, vol. 3, No. 1, Oxford, Taylor \& Francis.

Chein, F., M. Lemos and J. Assuncão (2007), "Desenvolvimento desigual: evidências para o Brasil”, Revista brasileira de economia, vol. 61, No. 3, Rio de Janeiro, Getulio Vargas Foundation.

Chen, H., J. Chen and J.D. Kalbfleisch (2004), "Testing for a finite mixture model with two components", Journal of the Royal Statistical Society Series B, vol. 66, No. 1, London, Royal Statistical Society. 
(2001), "A modified likelihood ratio test for homogeneity in finite mixture models", Journal of the Royal Statistical Society Series B, vol. 63, No. 1, London, Royal Statistical Society.

Da Mata, D. and others (2007), "Determinants of city growth in Brazil", Journal of Urban Economics, vol. 62, No. 2, Amsterdam, Elsevier.

Deb, P. and others (2009), "Job loss: eat, drink and try to be merry?", NBER Working Papers, No. 15122, Cambridge, Massachusetts, National Bureau of Economic Research.

Deb, P. and P. Trivedi (1997), "Demand for medical care by the elderly: a finite mixture approach", Journal of Applied Econometrics, vol. 12, No. 3, Hoboken, Wiley \& Sons.

Dixit, A. and J. Stiglitz (1977), "Monopolistic competition and optimum product diversity", American Economic Review, vol. 67, No. 3, Nashville, Tennessee, American Economic Association, June.

Duranton, G. and D. Puga (2000), "Diversity and specialization in cities: why, where and when does it matter?", Urban Studies, vol. 37, No. 3, Thousand Oaks, Sage Publications.

Frenken, K., F.G. Van Oort and T. Verburg (2007), "Related variety, unrelated variety and regional economic growth", Regional Studies, vol. 41, No. 5, Seaford, Regional Studies Association.

Fujita, M. (1988), "A monopolistic competition model of spatial agglomeration: differentiated product approach", Regional Science and Urban Economics, vol. 18, No. 1, Amsterdam, Elsevier.

Galinari, R. and others (2007), "O efeito de aglomeração sobre os salários industriais: uma aplicação ao caso brasileiro", Revista de economia contemporânea, vol. 11, No. 3, Rio de Janeiro, Institute of Economics, Rio de Janeiro's Federal University.

Glaeser, E. and others (1992), "Growth in cities", Journal of Political Economy, vol. 100, No. 6, Chicago, University of Chicago Press.

Härdle, W. and L. Simar (2003), Applied Multivariate Statistical Analysis, Berlin, MDTech.

Heckman, J. and B. Singer (1984), "A method of minimizing the distributional impact in econometric model for duration data", Econometrica, vol. 52, No. 2, New York, Econometric Society.

Henderson, J.V. (2003), "Marshall's scale economies", Journal of Urban Economics, vol. 53, No. 1, Amsterdam, Elsevier. (1986), "Efficiency of resource usage and city size", Journal of Urban Economics, vol. 19, No. 1, Amsterdam, Elsevier.

(1974), "The sizes and types of cities", American Economic Review, vol. 64, No. 4, Nashville, Tennessee, American Economic Association.

Henderson, J.V., A. Kuncoro and M. Turner (1995), "Industrial development in cities", Journal of Political Economy, vol. 103, No. 5, Chicago, University of Chicago Press.

IPEA (Institute of Economic Applied Research) (2006),
"Identificação, mapeamento e caracterização estrutural de arranjos produtivos locais no Brasil”, Brasilia.

IPEA/IBGE/UNICAMP (Institute of Economic Applied Research/ Brazilian Geographical and Statistical Institute/State University at Campinas) (2002), "Configuração atual e tendências da rede urbana", Configuração atual e tendências da rede urbana series, Brasilia.

Jacobs, J. (1969), The Economy of Cities, New York, Vintage.

Kaplan, D. (2005), "Finite mixture dynamic regression modeling of panel data with implications for dynamic response analysis", Journal of Educational and Behavioral Statistics, vol. 30, No. 2, Washington, D.C., American Educational Research Association.

Khalili, A. and J. Chen (2007), "Variable selection in finite mixtures of regression models", Journal of the American Statistical Association, vol. 102, Alexandria, American Statistical Association.

Krugman, P. (1993), "First nature, second nature, and metropolitan location", Journal of Regional Science, vol. 33, No. 2, Hoboken, Wiley Interscience.

(1991), "Increasing returns and economic geography", Journal of Political Economy, vol. 99, No. 3, Chicago, University of Chicago Press.

Laurini, M., E. Andrade and P. Pereira (2003), "Clubes de convergência de renda para os municípios brasileiros: uma análise não-paramétrica", document presented at the XXV Meeting of the Brazilian Econometric Society, Porto Seguro.

Lemos, M.B. and others (2003), "A nova configuração regional brasileira e sua geografia econômica”, Estudos econômicos, vol. 33, No. 4, São Paulo, University of São Paulo.

Marshall, A. (1920), Principles of Economics, London, MacMillan.

Mori, T. and A. Turrini (2005), "Skills, agglomeration, and segmentation", European Economic Review, vol. 49, No. 1, Amsterdam, Elsevier.

Quigley, J. (1998), "Urban diversity and economic growth", Journal of Economic Perspectives, vol. 12, No. 2, Nashville, Tennessee, American Economic Association.

Rivera-Batiz, F.L. (1988), "Increasing returns, monopolistic competition and agglomeration economies in consumption and production", Regional Science and Urban Economics, vol. 18, No. 1, Amsterdam, Elsevier.

Rosenthal, S. and W. Strange (2004), "Evidence on the nature and sources of agglomeration economies", Handbook of Regional and Urban Economics, Amsterdam, Elsevier.

(2003), "Geography, industrial organization, and agglomeration", The Review of Economics and Statistics, vol. 85, No. 2, Massachusetts, MIT Press.

Titterington, D., A. Smith and U. Markov (1985), Statistical Analysis of Finite Mixture Distributions, New York, Wiley \& Sons.

Wheaton, W. and M. Lewis (2002), "Urban wages and labor market agglomeration", Journal of Urban Economics, vol. 51, No. 3, Amsterdam, Elsevier. 